\title{
Logros y retos de la etnoeducación en Colombia ${ }^{1}$
}

\author{
Lilia Triviño Garzón ${ }^{*}$ \\ Libio Palechor Arévalo*
}

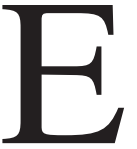

n Colombia encontramos una gran diversidad lingüística y cultural, manifiesta en 87 grupos indígenas, que hablan 65 lenguas y conforman el $1.75 \%$ de la población nacional. Igualmente encontramos un gran porcentaje de población afrodescendiente que constituye más del $18 \%$ de la población nacional; en dos casos específicos de dicha comunidad, se hablan lenguas criollas: el creole, en San Andrés y Providencia, y el palenquero en San Basilio de Palenque, cerca de Cartagena. También se encuentra el pueblo room o gitano que recientemente empieza a visibilizarse en la gran complejidad étnica del país.

\footnotetext{
${ }^{1}$ La primera parte de este artículo retoma algunos resultados del estudio realizado en el año 2004 sobre "Formación de docentes para la Educación Indígena Intercultural Bilingüe y/o Etnoeducación para Colombia", de las profesoras Patricia Cerón (actualmente docente de la Universidad de Nariño), Teresa Ramírez (profesora pensionada de la Universidad del Cauca) y Lilia Triviño (docente investigadora de la Universidad del Cauca), publicado en CD por la GTZ y el Ministerio de Educación de Bolivia en el año 2005.

* Docente investigadora del Departamento de Linguística de la Facultad de Ciencias Humanas y Sociales de la Universidad del Cauca. Grupo de investigaciones en Estudios Interculturales. Coordinadora del Punto Focal del PROEIB Andes para Colombia.

* Coordinador del Programa de Educación Intercultural Bilingüe -PEB del Consejo Regional Indígena del Cauca -CRIC. Representante de los pueblos indígenas en el PROEIB Andes.
} 
En este ambiente diverso, la etnoeducación es una construcción reciente, si se tiene en cuenta que en Colombia se empieza a hablar formalmente de esta modalidad educativa en la década de los '80 con la resolución 3454 de 1984, en cuyo artículo Nro.1 se expresa: "Los programas para la educación formal de las Comunidades Indígenas del país se orientarán y desarrollarán de acuerdo con la guía o lineamientos formulados por el Ministerio de Educación Nacional, enmarcados dentro del enfoque definido como ETNODESARROLLO y su componente educativo denominado ETNOEDUCACIÓN”. En consecuencia, la etnoeducación es una estrategia derivada de los planteamientos conceptuales del antropólogo mexicano Bonfild Batalla, que se retoman para promover un desarrollo propio dentro de las comunidades indígenas. Hoy en día, podemos apreciar que el concepto marcado por lo indígena se abre a la diversidad y convoca a diferentes poblaciones, lo que genera nuevos retos y problemáticas a nivel del ser y el hacer de la misma.

A fin de dar cuenta de algunos logros y retos de la etnoeducación en Colombia, en este artículo se hará referencia a ellos desde dos perspectivas: de una parte, desde los programas de formación, en especial a nivel de Educación Superior y de otra, desde el marco político administrativo actual.

\section{Primera parte:}

Logros y retos de la etnoeducación en el espacio de formación en Educación Superior

Contextualización

La década de los '70 resulta muy significativa en términos del desarrollo de las luchas reivindicativas indígenas, que a nivel colombiano y latinoamericano promovieron un 
gran movimiento alrededor de la recuperación de territorios ancestrales, además del fortalecimiento cultural y la generación de procesos autonómicos. En este período se inició la conformación de organizaciones indígenas a nivel regional y local, tales como el Consejo Regional Indígena del Cauca-CRIC y la Organización Indígena Tayrona de la Sierra Nevada de Santa Martha -CIT, entre otras. Estas dos experiencias marcaron un hito en relación con la educación indígena: el primero porque inició la creación de escuelas propias y la formación de maestros bilingües seleccionados por las comunidades, y la segunda, porque fueron los primeros en solicitar la administración de la educación a raíz de la expulsión de los Misioneros Capuchinos de sus comunidades, a razón de que la educación que impartieron desde 1916 hasta 1976, no respondía a las necesidades del contexto económico, social y cultural.

En la década del '80 se siguieron creando organizaciones indígenas regionales y zonales, dando origen a la Coordinadora Nacional Indígena hasta que finalmente, en 1983 se conformó la Organización Nacional Indígena de Colombia -ONIC, la cual cuenta hoy con más de 30 organizaciones indígenas regionales, 200 organizaciones zonales y más de 800 cabildos afiliados (ONIC:2000:32). También surgen otras organizaciones de importancia a nivel macrorregional como las Autoridades Indígenas de Colombia (AICO) y Organización de los Pueblos Indígenas de Amazonas y Caquetá (OPIAC).

El fortalecimiento organizativo local, regional y nacional y la implementación de programas educativos alternativos al enfoque oficial, generan fuertes presiones sobre el aparato oficial, de tal forma que el Estado colombiano se ve obligado a facilitar unas políticas educativas más favorables a las particularidades de estas poblaciones.

En 1986 se expide el Decreto Ley 088 de 1976 mediante el cual se reorganiza el Ministerio de Educación 
Nacional -MEN, y se abre la posibilidad para que los grupos étnicos construyan propuestas de educación propia y participen activamente en la elaboración de sus currículos. En 1978, el Decreto 1142 reglamenta el artículo 11, a fin de ratificar el derecho de los indígenas a tener educación propia en su lengua materna y de acuerdo con sus características culturales. Posteriormente, el Decreto 085 de 1980 faculta el nombramiento de maestros bilingües para ejercer la docencia en grupos indígenas, aunque no cubran los requisitos exigidos a los demás docentes de la nación. En 1984, con la resolución 3454 , se crea el grupo de etnoeducación del Ministerio para incentivar programas etnoeducativos en los pueblos indígenas.

En 1991, con la expedición de la reforma Constitucional, se logra la expresión más significativa a nivel normativo. Los artículos 7, 8,10, 13, 67 y 68 son muy importantes en relación con el reconocimiento de la diversidad étnica y cultural y la oficialización de las lenguas indígenas en sus territorios y en la formación docente. Estos planteamientos se retoman y amplían en la Ley General de Educación -Ley 115- de 1994, que en el articulado del capítulo $3^{\circ}$ define la etnoeducación como la educación dirigida a grupos étnicos, incluidos los afrocolombianos, rom y raizales. Igualmente en los artículos mencionados se formulan los principios y fines teniendo en cuenta los criterios de integralidad, interculturalidad, diversidad lingüística, participación comunitaria, flexibilidad y progresividad. Se determina que la enseñanza sea bilingüe en los territorios de los grupos étnicos con tradición lingüística propia, tomando como base la lengua ancestral, y se legisla sobre la selección y formación de educadores en el dominio de las lenguas y culturas de los pueblos (MEN 2004).

Como se puede apreciar, el Estado ha respondido a nivel normativo a las demandas de los pueblos indígenas y afrocolombianos; (Ver tabla 1) sin embargo, la implementa- 
ción de la Ley aún es insuficiente en unos casos y en otros, es contraria al espíritu de la misma. Dado que si bien los postulados de la etnoeducación son afines con los de los pueblos indígenas, se presentan divergencias como lo planteamos en el estudio sobre formación de docentes para la educación indígena intercultural bilingüe y etnoeducación para Colombia:

\section{TABLA 1: \\ Normatividad sobre formación \\ De maestros en educación indígena y/o \\ Etnoeducación y experiencias Significativas}

\begin{tabular}{|c|c|c|c|}
\hline & $\begin{array}{c}\text { NORMAS } \\
\text { GENERALES } \\
\text { SOBRE } \\
\text { EDUCACIÓN } \\
\text { INDÍGENA YIO } \\
\text { ETNOEDUCACIÓN }\end{array}$ & $\begin{array}{l}\text { NORMATIVA } \\
\text { QUE REGULAN } \\
\text { LA FORMACIÓN } \\
\text { DOCENTE } \\
\text { SELECCIÓN DE } \\
\text { EDUCADORES }\end{array}$ & $\begin{array}{l}\text { EXPERIENCIAS } \\
\text { DE FORMACIÓN } \\
\text { DE MAESTROS }\end{array}$ \\
\hline $\begin{array}{l}1970 \text {-80 } \\
\text { Surgimiento de } \\
\text { organizaciones } \\
\text { indígenas regio- } \\
\text { nales. } \\
\text { Inicio de expe- } \\
\text { riencias educati- } \\
\text { vas autónomas } \\
\text { locales -Sierra } \\
\text { Nevada y CRIC. } \\
1980 \text { - } 90 \\
1981 . \text { S u r g i- } \\
\text { miento de la } \\
\text { Organización } \\
\text { Nacional Indíge- } \\
\text { na de Colombia } \\
\text {-ONIC. } \\
\text { Conformación de } \\
\text { nuevas organiza- }\end{array}$ & $\begin{array}{l}\text { LINE A M IEN TOS } \\
\text { GENERALES DE } \\
\text { EDUCACIÓN INDÍ- } \\
\text { GENA } \\
\text { 1976. El Decreto 088 } \\
\text { estableció el derecho } \\
\text { de las comunidades } \\
\text { indígenas a recibir } \\
\text { educación acorde con } \\
\text { sus culturas. La regla- } \\
\text { mentación de 1978, } \\
\text { mediante el Decreto } \\
\text { 1142, especifica el } \\
\text { derecho a la educa- } \\
\text { ción en lengua mater- } \\
\text { na y de acuerdo con } \\
\text { características cultu- } \\
\text { rales. } \\
\text { ETNOEDUCACIÓN } \\
\text { 1984. Resolución } \\
\text { 3454 - Establecimien- } \\
\text { to de unos lineamien- } \\
\text { tos de Educación Indí- }\end{array}$ & $\begin{array}{l}\text { 1978 Decreto } 1142 \\
\text { Art. 11. En cuanto a la } \\
\text { selección, formación } \\
\text { y capacitación : } \\
\text { 1. Siempre que sea } \\
\text { posible, los maestros } \\
\text { serán seleccionados } \\
\text { por las comunidades } \\
\text { indígenas entre los } \\
\text { miembros de la } \\
\text { misma comunidad. } \\
\text { 2. El maestro deberá } \\
\text { ser bilingüe, o sea } \\
\text { comprobar, además } \\
\text { de la idoneidad para } \\
\text { el ejercicio docente, } \\
\text { conocimientos míni- } \\
\text { mos de la lengua } \\
\text { materna y del espa- } \\
\text { ñol. } \\
3 . \text { La Dirección de } \\
\text { capacitación y Perfec- } \\
\text { cionamiento Docente, } \\
\text { Currículo y Medios } \\
\text { Educativos, diseñará }\end{array}$ & $\begin{array}{l}\text { les inicial y primaria. } \\
\text { C A PA C ITA C IÓ N } \\
\text { D E M A E S T R O S } \\
\text { INDíGENAS } \\
\text { Cursos de nivela- } \\
\text { ción y actualización } \\
\text { (no conducentes a } \\
\text { títulos): } \\
\text { - Desde las mismas } \\
\text { organizaciones indí- } \\
\text { genas tales como: } \\
\text { Consejo Regional } \\
\text { Indígena del Cauca- } \\
\text { CRIC, Consejo } \\
\text { Regional Indígena } \\
\text { del Tolima-CRIT } \\
\text {-Algunas experiencias } \\
\text { con el apoyo de misio- } \\
\text { neros y/o Educación } \\
\text { Contratada: } \\
\text { Organización Regio- } \\
\text { nal Embera Waunana- }\end{array}$ \\
\hline
\end{tabular}




\begin{tabular}{|c|c|c|c|}
\hline & $\begin{array}{r}\text { NOI } \\
\text { GENE } \\
\text { SO } \\
\text { EDUC } \\
\text { INDÍG } \\
\text { ETNOED }\end{array}$ & $\begin{array}{l}\text { NORMATIVA } \\
\text { QUE REGULAN } \\
\text { LA FORMACIÓN } \\
\text { DOCENTE } \\
\text { SELECCIÓN DE } \\
\text { EDUCADORES }\end{array}$ & $\begin{array}{l}\text { EXPERIENCIAS } \\
\text { DE FORMACIÓN } \\
\text { DE MAESTROS }\end{array}$ \\
\hline $\begin{array}{l}\text { ciones indígenas } \\
\text { r e g i o n a l e s. } \\
\text { Actualmente hay } \\
\text { más de } 60 \text { en el } \\
\text { país. } \\
\text { 1985. Primer Se- } \\
\text { minario Nacional } \\
\text { de Etnoeduca- } \\
\text { ción. MEN -ONIC. } \\
\text { En esta déçada } \\
\text { surgen dos pro- } \\
\text { gramas a nivel de } \\
\text { Postgrado en el } \\
\text { país: Universidad } \\
\text { de los Andes: } \\
\text { Maestría en Etno- } \\
\text { ligüística (con } \\
\text { amplia participa- } \\
\text { ción de indígenas) } \\
\text { y } \text { n i v r r i da d } \\
\text { Nacional: Maes- } \\
\text { tría en Lingüística } \\
\text { 1990-2000 } \\
\text { 1991. Reforma } \\
\text { constitucional artí- } \\
\text { culos } 7,8 \text {, el Esta- } \\
\text { do reconoce y } \\
\text { protege la diversi- } \\
\text { dad lingüística y } \\
\text { cultural de la } \\
\text { Nación. } \\
\text { Art.10, dispone } \\
\text { que la enseñanza } \\
\text { que se imparta en } \\
\text { las comunidades } \\
\text { con tradición lin- }\end{array}$ & $\begin{array}{l}\text { gena nacional bajo el } \\
\text { enfoque definido } \\
\text { como Etnodesarrollo } \\
\text { y su componente } \\
\text { educativo denomina- } \\
\text { do } \\
\text { ETNOEDUCACIóN. } \\
\text {-Creación del Grupo } \\
\text { de Etnoeducación del } \\
\text { Ministerio para incen- } \\
\text { tivar programas etno- } \\
\text { educativos. } \\
\text { 1993. Ley 70, ofrece } \\
\text { los mecanismos de } \\
\text { protección y desarro- } \\
\text { llo de los derechos de } \\
\text { los afrocolombianos, } \\
\text { incluida la educación. } \\
\text { Da origen a la crea- } \\
\text { ción de la Cátedra de } \\
\text { Estudios Afrocolom- } \\
\text { bianos que desde } \\
\text { 1998 se plantea para } \\
\text { toda la enseñanza } \\
\text { básica y media en el } \\
\text { área de Ciencias } \\
\text { Sociales. } \\
\text { 1994: Ley General } \\
\text { de Educación, defi- } \\
\text { ne la etnoeducación } \\
\text { para los grupos étni- } \\
\text { cos afrocolombianos, } \\
\text { room (gitanos) y rai- } \\
\text { zales; incluye la for- } \\
\text { mación de etnoedu- } \\
\text { cadores para grupos } \\
\text { étnicos. } \\
\text { 1995: Decreto } 804\end{array}$ & $\begin{array}{l}\text { el currículo para la } \\
\text { formación y capaci- } \\
\text { tación del personal } \\
\text { docente de las } \\
\text { comunidades indíge- } \\
\text { nas teniendo en } \\
\text { cuenta lo estableci- } \\
\text { do. } \\
\text { 1980: Decreto 085, } \\
\text { faculta el nombra- } \\
\text { miento de personas } \\
\text { bilingües avaladas } \\
\text { por las comunidades } \\
\text { como maestros, aun } \\
\text { sin cumplir requisitos } \\
\text { de formación acadé- } \\
\text { mica. } \\
\text { 1986: Resolución } \\
\text { No.9549. Autoriza un } \\
\text { sistema especial } \\
\text { para la profesionali- } \\
\text { zación de maestros } \\
\text { indígenas a través } \\
\text { de las Escuelas Nor- } \\
\text { males. } \\
\text { En los lineamientos } \\
\text { de la cátedra se } \\
\text { establece que la for- } \\
\text { mación de los edu- } \\
\text { cadores debe reali- } \\
\text { zarse en coordina- } \\
\text { ción con las Comi- } \\
\text { siones Pedagógicas } \\
\text { Departamentales y } \\
\text { Regionales. } \\
\text { Ley General de } \\
\text { Educación } \\
\text { Art. } 58 \text {. El Estado } \\
\text { promoverá y fomen- }\end{array}$ & $\begin{array}{l}\text { OREWA, UNUMA, } \\
\text { Consejo regional } \\
\text { Indígena del Vau- } \\
\text { pés-CRIVA y ORIST } \\
\text { en el Vichada. } \\
\text { PROFESIONALI- } \\
\text { ZACIÓN DE MAES- } \\
\text { TROS: } \\
\text { "16 procesos de } \\
\text { profesionalización } \\
\text { de maestros indíge- } \\
\text { nas en 16 departa- } \\
\text { mentos en convenio } \\
\text { con las Escuelas } \\
\text { Normales, } 2000 \\
\text { docentes de } 40 \text { pue- } \\
\text { blos indígenas" } \\
8 \text { PROGRAMAS A } \\
\text { NIVEL } \\
\text { DE PREGRADo } \\
\text { 1992 Universidad } \\
\text { de la Amazonía, } \\
\text { Licenciatura en Lin- } \\
\text { güística y Educación } \\
\text { Indígena. } \\
\text { 1995. Universidad } \\
\text { del Cauca, Licencia- } \\
\text { tura en Etnoeduca- } \\
\text { ción. } \\
\text { 1995, Universidad } \\
\text { de la Guajira, Licen- } \\
\text { ciatura en Etnoedu- } \\
\text { cación. } \\
\text { 1995. Universidad } \\
\text { Tecnológica y Peda- }\end{array}$ \\
\hline
\end{tabular}

2 AGREDA, Antonia. La etnoeducación: una respuesta a las aspiraciones educativas de los pueblos indígenas de Colombia, en Abriendo Caminos. Pág. 223.

150 


\begin{tabular}{|c|c|c|c|}
\hline XTO & $\begin{array}{c}\text { NORMAS } \\
\text { GENERALES } \\
\text { SOBRE } \\
\text { EDUCACIÓN } \\
\text { INDÍGENA Y/O } \\
\text { ETNOEDUCACIÓN }\end{array}$ & $\begin{array}{c}\text { NORMATIVA } \\
\text { QUE REGULAN } \\
\text { LA FORMACIÓN } \\
\text { DOCENTE } \\
\text { SELECCIÓN DE } \\
\text { EDUCADORES }\end{array}$ & $\begin{array}{l}\text { EXPERIENCIAS } \\
\text { DE FORMACIÓN } \\
\text { DE MAESTROS }\end{array}$ \\
\hline $\begin{array}{l}\text { güística propia, } \\
\text { será bilingüe. } \\
\text { Art.67, reconoce } \\
\text { la educación co- } \\
\text { mo un derecho } \\
\text { de la persona y } \\
\text { un servicio públi- } \\
\text { co que tiene una } \\
\text { función social, } \\
\text { por tanto, debe } \\
\text { ser garantizada } \\
\text { por el Estado. } \\
\text { Art. } 68 \text {, señala } \\
\text { que todos los gru- } \\
\text { pos étnicos ten- } \\
\text { drán derecho a } \\
\text { una formación } \\
\text { que respete y } \\
\text { desarrolle su } \\
\text { identidad cultural. } \\
\text { 1991 Ley } 21 . \text { Es } \\
\text { la ley aprobatoria } \\
\text { del Convenio } 169 \\
\text { de la OlT. } \\
1992-2003 \text { Crea- } \\
\text { ción de progra- } \\
\text { mas de formación } \\
\text { en Educación } \\
\text { Indígena y Etnoe- } \\
\text { ducación a nivel } \\
\text { universitario. } \\
20 \text { o } 30 \text { o } 5 \\
\text { Mesas naciona- } \\
\text { les y regionales } \\
\text { de concertació. }\end{array}$ & $\begin{array}{l}\text { reglamentario del } \\
\text { Título III de la Ley } \\
\text { 115: Educación para } \\
\text { grupos étnicos. Seña- } \\
\text { la los principios de la } \\
\text { Etnoeducación; pro- } \\
\text { cesos de formación } \\
\text { de etnoeducadores; } \\
\text { orientación curricular, } \\
\text { seguimiento, evalua- } \\
\text { ción, administración y } \\
\text { gestión. } \\
\text { 1999 Circular } 51 \\
\text { ordena la evaluación } \\
\text { de docentes de edu- } \\
\text { cación indígena (sólo } \\
\text { de los pagados por el } \\
\text { Estado), concertada } \\
\text { con las organizacio- } \\
\text { nes indígenas, con } \\
\text { base en las disposi- } \\
\text { ciones mencionadas. } \\
\text { 2003: Directiva Minis- } \\
\text { terial abre proceso de } \\
\text { recesión de contratos } \\
\text { "educación contrata- } \\
\text { da" con la Iglesia } \\
\text { Católica y su transfe- } \\
\text { rencia a los entes } \\
\text { territoriales a pedido } \\
\text { de las Asociaciones } \\
\text { de Capitanes Indíge- } \\
\text { nas del Amazonas. } \\
\text { 2004 Decreto } 3238, \\
\text { por el cual se regla- } \\
\text { mentan los concursos } \\
\text { que rigen la carrera } \\
\text { docente y se determi- } \\
\text { nan criterios, conteni- } \\
\text { dos y procedimientos } \\
\text { para su aplicación. }\end{array}$ & $\begin{array}{l}\text { tará la formación de } \\
\text { educadores en el } \\
\text { dominio de las cultu- } \\
\text { ras y lenguas de los } \\
\text { grupos étnicos, así } \\
\text { como en programas } \\
\text { sociales de difusión } \\
\text { de las mismas. } \\
\text { Art. 62. Las autorida- } \\
\text { des competentes, en } \\
\text { concertación con los } \\
\text { grupos étnicos, } \\
\text { seleccionarán a los } \\
\text { educadores que } \\
\text { laboren en sus terri- } \\
\text { torios, preferiblemen- } \\
\text { te entre los miem- } \\
\text { bros de las comuni- } \\
\text { dades...Dichos edu- } \\
\text { cadores deberán } \\
\text { acreditar formación } \\
\text { en etnoeducación, } \\
\text { poseer conocimien- } \\
\text { tos básicos del res- } \\
\text { pectivo grupo étnico, } \\
\text { en especial de su } \\
\text { lengua materna ade- } \\
\text { más del castellano. } \\
\text { Recoge el espíritu de } \\
\text { lo planteado en la } \\
\text { Ley General de Edu- } \\
\text { cación sobre forma- } \\
\text { ción y selección de } \\
\text { maestros indígenas. } \\
\text { 1997: Decreto } 3012, \\
\text { Escuelas Normales } \\
\text { Superiores, habilita- } \\
\text { das para formación } \\
\text { docente en los nive- }\end{array}$ & $\begin{array}{l}\text { gógica de Pereira, } \\
\text { Licenciatura en } \\
\text { Etnoeducación y } \\
\text { Desarrollo Comuni- } \\
\text { tario. } \\
\text { 1997. Universidad } \\
\text { Tecnológica y Peda- } \\
\text { gógica de Pereira, } \\
\text { Licenciatura en } \\
\text { Educación Indíge- } \\
\text { na. } \\
\text { 2000. Universidad } \\
\text { Pontificia Bolivaria- } \\
\text { na, Licenciatura en } \\
\text { Etnoeducación. } \\
\text { 2000. Universidad } \\
\text { Nacional a Distancia } \\
\text { UNAD, Licenciatura } \\
\text { en Etnoeducación. } \\
\text { 2003. Universidad } \\
\text { Mariana, Licenciatu- } \\
\text { ra en Etnoeduca- } \\
\text { ción. } \\
\text { Normales implica- } \\
\text { das en estos pro- } \\
\text { cesos: } \\
\text {-Normal de Los } \\
\text { Andes, municipio de } \\
\text { La Vega en el } \\
\text { Cauca. } \\
\text {-Normal de Manau- } \\
\text { re en Cesar. } \\
\text {-Normal de Lorica } \\
\text { en Córdoba. } \\
\text {-Normal de Barba- } \\
\text { coas en Nariño. }\end{array}$ \\
\hline
\end{tabular}


Fuente. Elaboración propia a partir de los Lineamientos de Educación Indígena de 1996; Memorias del Primer Seminario de Etnoeducación, de la Constitución Nacional; Ley General de Educación y documentos de las Normales y Universidades.

Los principios de la etnoeducación que aparecen en la legislación nacional coinciden con los que postulan las organizaciones de los grupos étnicos, toda vez que estos últimos los han exigido al Estado y porque son la convalidación de procesos experimentales implementados en sus regiones. Sin embargo, estos principios pueden ser interpretados $y$ aplicados de manera muy diferente o a veces opuesta, puesto que la etnoeducación oficial es aplicable fundamentalmente a la educación escolarizada, mientras que para los grupos étnicos la escuela es "fuente de prestigio y espacio para el aprendizaje del español, matemáticas y otros conocimientos necesarios para interactuar con otros pueblos y con la sociedad mayoritaria" (Lozano y otros 2000: 23), pero no es apropiada para incluir ni sus saberes, ni sus comportamientos. Escolarizar los conocimientos culturales específicos no parece estar dando resultado, de manera que la lucha por la educación propia recomienza. (Triviño, Cerón y Ramírez: 2005: 16).

Otro punto relevante en relación con la Etnoeducación, es que pasó de ser concepto y práctica excluyente (solo para indígenas) a ser incluyente; los afrocolombianos y los room están siendo cubiertos por esta modalidad educativa como lo mencionamos anteriormente, pero también mestizos de zonas marginales urbanas empiezan a percibirla como una alternativa frente a la que crisis que vive el país. Esto último se manifiesta en la demanda que tienen 
actualmente los programas de formación en Educación Superior en Etnoeducación y el interés por investigar sobre las particularidades culturales de las poblaciones que habitan dichos sectores, en la perspectiva de mejorar la convivencia intercultural.

Concomitante con esta situación está el empleo de las diferentes denominaciones que se usan según contextos y momentos de desarrollo que tienen las organizaciones indígenas, tales como: "educación endógena", "educación tradicional”, "educación propia”, "educación indígena”, "educación intercultural" "educación bilingüe" "educación intercultural bilingüe", "educación comunitaria", que van apareciendo como formas de diferenciar procesos, experiencias y expectativas frente a lo que plantea el Estado colombiano. Estas concepciones también se caracterizan por ser problemáticas pues según tendencias regionales, políticas, momentos y escenarios, se hace referencia a ellas, por ejemplo, cuando se habla de Educación Propia, término que hoy en día aparece con frecuencia en el discurso de las organizaciones indígenas, se tiene que para algunos es una reinvindicación política, un ejercicio de autonomía; mientras que para otros es la educación que se da en espacios comunitarios, orientada por los padres de familia y por los mayores de la comunidad, educación que no pasa ni por la escritura ni por la lectura:

La educación propia no está escrita, no se enseña únicamente en las aulas, se enseña en la casa, en el campo, en diferentes lugares de la comunidad, por ejemplo: aprender a saludar y respetar a los mayores, no se aprende en la escuela, sino en el lugar en donde están los mayores; se aprende en la práctica, cuando se lleva al niño y se le dice: primero se saluda a los mayores y luego a las mujeres. Otra enseñanza es no sentarse en una silla ajena hasta que no 
se la brinden. Para aprender a ordeñar, los abuelos levantan al niño a las cinco de la mañana; también le cuentan los mitos sobre el origen de la comunidad, para que los aprendan. Cuando se llega a los 12 años ya se sabe de plantas tradicionales" (Estudiante inga del Diplomado en Gestión Etnoeducativa).

Otra perspectiva desde la cual se aborda este enfoque educativo es:

La educación propia es un paraguas amplio, implica que la comunidad pueda orientar, pueda construir si quiere construir, si necesita ejecutar, pueda desarrollar desde su propia perspectiva, pueda controlar, pueda evaluar la educación. La educación es como una columna central, como un eje de la cultura, pero de acuerdo con las necesidades, de acuerdo con los problemas, de acuerdo con las vivencias. La educación propia después se constituye en un sistema, en un engranaje. (Orientadora del CRIC del Diplomado en Gestión Etnoeducativa).

En este actual ambiente de tensiones las políticas de los pueblos indígenas se consolidan a través de los planes de vida, en los que cada pueblo plasma su devenir en los diferentes aspectos socioculturales y económicos, y sobre esta base se construyen los Proyectos Educativos Comunitarios -PEC, estrategia que permite que la educación sea una herramienta fundamental en la pervivencia de los pueblos. La proyección a mediano plazo para las organizaciones indígenas es contar con un sistema educativo propio, en el cual se formulen proyectos de vida y se trabaje de forma holística desde el ámbito familiar hasta la formación universitaria. En la segunda parte de este artículo se habla de este aspecto en forma más amplia. 


\section{Formación docente}

La formación de docentes para la etnoeducación en Colombia se ha realizado a partir de programas de nivelación, capacitación, actualización, profesionalización y de educación superior. Con excepción de los programas de formación en Educación Superior, los demás han sido gestados casi en su mayoría por las organizaciones indígenas, quienes han buscado los recursos humanos y económicos para su realización: Secretarías de Educación, Ministerio de Educación, Normales Superiores, Educación Contratada, ONGs y algunas Universidades, entre otros, y han acompañado los procesos en su gestión académica.

Los cursos de nivelación, capacitación y actualización se dieron principalmente en las experiencias propias de las comunidades, ya que los maestros que nombraron eran dirigentes locales que cumplían más con un perfil político que de académico; su rol principal fue de agentes políticos culturales, antes que de agentes educativos. La formación que recibieron fue a través de talleres, seminarios, reuniones, asambleas y desde una perspectiva muy particular, tal como lo expresa el CRIC:

"¿En qué sentido se formaron los participantes en este proceso? Todos tuvieron que reenfocar su propia visión de qué era la educación: su papel en la comunidad indígena y en la sociedad en general, quién enseñaba y quién aprendía, dónde se enseñaba y dónde se aprendía, de acuerdo con qué criterios se generaba una metodología y un contenido de aprendizaje y de enseñanza, cómo se investigaban las necesidades locales, regionales y cómo se ligaban las exigencias de la educación. Igualmente, de vital importancia fue la reflexión y reconocimiento de las lenguas, historias y usos culturales, que no eran 
solamente contenidos de la educación, sino fundamentos de ella" (2004:56).

La formalización de estos procesos se hizo a través de la profesionalización de maestros indígenas desde 1986, con la resolución 9549, en la cual se dispuso que el Ministerio de Educación Nacional organizara un proceso especial de profesionalización de maestros, en correspondencia con las solicitudes y demandas de los pueblos indígenas. Estos procesos tuvieron la impronta de las experiencias de capacitación adelantadas por algunas organizaciones indígenas, que básicamente buscaban el fortalecimiento cultural de los sujetos, para que de manera autónoma pudieran incorporar elementos de las otras culturas y asumieran un rol de liderazgo en los procesos de educación intercultural. La investigación colectiva como forma de construcción de proyectos de vida y el papel preponderante de las lenguas ancestrales en los procesos, fueron los principales aspectos que se tuvieron en cuenta.

Hasta este nivel de formación de maestros indígenas, la regulación y protagonismo de algunas organizaciones y comunidades indígenas del suroccidente colombiano son aspectos muy importes a ser considerados en este recorrido por los procesos de formación, porque fueron experiencias que contribuyeron al desarrollo de los mismos, en términos de definición de currículos para la básica primaria, contenidos, investigación y elaboración de materiales. También se puede resaltar, que estas experiencias fueron un aprendizaje de trabajo conjunto con las instituciones antes mencionadas y un modo de permear hasta cierto punto unas nuevas maneras de formar recursos humanos superando la visión individualista, disciplinar y profesionalizante que ha caracterizado la educación en general.

La profesionalización cumplió con diferentes propósitos, tal como lo enunciamos en el estudio sobre Formación en Educación Intercultural Bilingüe: 
La profesionalización también ha servido para preparar a los maestros para el acceso a la educación superior, que abarca tanto la formación en el ciclo complementario en las Normales Superiores, como las licenciaturas en las Universidades. Todos los programas de profesionalización tuvieron una orientación eminentemente pedagógica y cultural, pues se trató de preparar a los indígenas en saberes y metodologías de enseñanza que pudieran ser aplicadas en las escuelas. Si bien la profesionalización se programó con propósitos de mejoramiento de la calidad de la educación y en respuesta a las demandas de las organizaciones, en la práctica sus efectos tuvieron que ver con la inscripción al escalafón docente, la legalización de la actividad profesional de los educadores y la necesidad de contratación oficial a docentes que laboraban sin remuneración económica. (Triviño, Cerón y Ramírez: 2005).

Estos cursos también permitieron la titulación como bachilleres pedagógicos de muchos maestros indígenas y no indígenas que trabajaban en sus territorios, lo que generó la expectativa de continuar por el camino de la formación académica. Surge de esta manera la demanda por la formación en Educación Superior.

Una vez que en el país se contó con bachilleres pedagógicos indígenas, las Universidades empezaron a formular propuestas en Educación Indígena y Etnoeducación. La participación de algunas de ellas en los procesos de profesionalización y su relación con las comunidades y organizaciones indígenas, junto con el marco legislativo, como lo presentamos en la tabla 1, fueron insumos definitivos en la construcción de las propuestas. Actualmente existen en el país ocho programas para la formación de recursos humanos: dos de ellos en Educación Indígena y seis en Etnoeducación, a saber: 
-Universidad de la Amazonia: Licenciatura en Lingüística y Educación Indígena.

-Universidad Tecnológica y Pedagógica de Pereira -UTP: Licenciatura en Educación Indígena y Licenciatura en Etnoeducación y Desarrollo Comunitario (población no indígena).

-Universidad del Cauca: Licenciatura en Etnoeducación.

-Universidad de la Guajira: Licenciatura en Etnoeducación.

-Universidad Nacional Abierta y a Distancia -UNAD: Licenciatura en Etnoeducación.

-Universidad Pontificia Bolivariana: Licenciatura en Etnoeducación.

-Universidad Mariana: Licenciatura en Etnoeducación.

Los programas de formación de formadores, que ya existían en el año 1998 y los que se crearon posteriormente, debieron cumplir con los planteamientos esbozados por el Sistema Nacional de Formación de Educadores sobre Acreditación Previa. El Decreto 278 demandó la necesidad de incluir los núcleos del saber pedagógico: educabilidad del ser humano, enseñabilidad de las disciplinas, estructura histórica y epistemológica de la pedagogía, realidades y tendencias sociales y educativas de la profesión. Esta exigencia provocó la reestructuración curricular de los programas que estaban funcionando para lograr su inscripción en el sistema nacional de acreditación. Los procesos para el cumplimiento de los requisitos para optar a la Acreditación Previa fueron muy importantes, pues incluyeron una revisión a profundidad de los perfiles, currículos, materiales de apoyo, recursos humanos y logísticos, mediante un sistema de evaluación que incluyó a estudiantes, egresados, administrativos, directivas, profesores e infraestructura. Por tanto, en la malla curricular de estos programas encontramos este eje pedagógico como rasgo común (ver tabla 2 ), pero además hay otras afinidades que comentaremos a 
continuación, a partir de tendencias predominantes, sin negar que se presentan especificidades según regiones y criterios de las Universidades.

La modalidad semipresencial en el desarrollo de las distintas propuestas es uno de los aspectos comunes de los programas; sin embargo, la Universidad de la Guajira también ofrece el programa en la modalidad presencial nocturna, al igual que la Tecnológica y Pedagógica de Pereira en la Licenciatura que realiza con población no indígena.

Esta coincidencia está asociada al deseo de ampliar la cobertura y contribuir con la capacitación de recursos humanos que laboran en zonas apartadas de los centros urbanos.

Normalmente las fases presenciales se realizan en épocas de vacaciones y mediante encuentros en fines de semana; durante el tiempo no presencial los estudiantes realizan actividades de autoformación, para lo cual se cuenta con materiales de apoyo elaborados por las Universidades y lecturas de material bibliográfico, además realizan los ejercicios de investigación y la práctica pedagógica.

De acuerdo con los objetivos de la formación de etnoeducadores, los programas de licenciatura articulan las dimensiones étnica, política, pedagógica y de gestión comunitaria para formar profesionales que respondan a las siguientes características:

\section{- Líderes comunitarios}

Este rasgo permite señalar un aspecto predominante en el perfil de formación, porque centra a los sujetos en una dinámica de compromiso con sus comunidades, motivando la constitución de agentes educativos que promuevan procesos comunitarios de desarrollo y el fortalecimiento de las formas organizativas comunitarias. 


\section{- Gestores educativos}

Algunos programas buscan formar licenciados que desde una perspectiva integral sean capaces de desempeñar diversas acciones relacionadas con el diseño, ejecución, supervisión, evaluación y administración de programas curriculares para las escuelas indígenas. En otros casos, se busca que sean impulsores de propuestas educativas no solo en ámbitos escolarizados sino de interés comunitario basadas en el respeto a la diferencia y el reconocimiento del otro.

- Investigadores

En la mayoría de los programas es claro el papel de la investigación como espacio de formación y transformación de la acción o la práctica, articulada a procesos de interés comunitario tales como: lenguas, culturas, política, prácticas y saberes pedagógicos, problemáticas económicas, sociales y ambientales de las comunidades. Todo ello bajo el interés de formar en y desde una docencia investigativa.

- Sujetos interculturales

Se busca fortalecer el reconocimiento de las particularidades étnicas, al igual que la capacidad para establecer relaciones interculturales y multiculturales que aporten en la construcción de sociedades más democráticas.

En cuanto a los planes de estudio, los ocho programas existentes cuentan con los componentes de comunicación y lenguaje, pedagógico, investigativo; en cinco de ellos aparece lo relacionado con el ambiente y la naturaleza; en igual proporción aparece lo social y cultural; finalmente, en 
dos programas solamente se tiene el componente de gestión comunitaria. (Ver tabla 2).

Todo parece indicar que el importante desarrollo alcanzado en cuanto al estudio de las lenguas, gracias a los postgrados de la Universidad de los Andes con el Centro Colombiano de Estudios en Lenguas Aborígenes -CCELA, la Universidad Nacional de Colombia, y en menor grado las Universidades de Antioquia, Valle y Cauca, ha generado que el país cuente con la descripción de más de cuarenta lenguas, lo cual constituye un fundamento para el trabajo de formación en ese campo. Sin embargo, la ausencia de unas políticas claras frente al papel y uso de las lenguas en las escuelas hace que los procesos de educación bilingüe sean aún deficientes.

A lo anterior se une el debilitamiento en el uso de las lenguas indígenas y criollas en los espacios familiares y comunitarios por parte de los jóvenes, lo cual representa un serio riesgo dado que las nuevas generaciones cada día se ven más apartadas de la necesidad de comunicarse en sus lenguas maternas. Sin embargo, hay importantes iniciativas en favor de la recuperación y fortalecimiento de las lenguas.

Es de anotar que otro aspecto problemático son los escasos avances en la construcción de metodologías que dinamicen las lenguas en sus múltiples funciones tanto en la escuela y como en los espacios comunitarios.

Como logro se puede destacar que algunos programas como los de las Universidades del Cauca y la Guajira han articulado la enseñanza de lenguas indígenas como parte del proceso de formación, lo que significa visibilizar las lenguas indígenas, sensibilizar a los estudiantes hacia estas lenguas y que los indígenas hablantes de una lengua tengan la oportunidad de conocer otras. También significa que se articulen docentes bilingües a los programas. 


\section{Tabla 2:}

Ejes de las estructuras curriculares de 7 licenciaturas en etnoeducación

\begin{tabular}{|c|c|c|c|c|c|c|}
\hline $\begin{array}{c}\text { U. de la } \\
\text { Amazonia }\end{array}$ & $\begin{array}{l}\text { U. del } \\
\text { Cauca }\end{array}$ & $\begin{array}{l}\text { U. de la } \\
\text { Guajira }\end{array}$ & $\begin{array}{c}\text { U. } \\
\text { Mariana }\end{array}$ & \begin{tabular}{|c|} 
UTP \\
Lic. Indígena $^{3}$
\end{tabular} & $\begin{array}{l}\text { U. Pontificia } \\
\text { Bolivariana }\end{array}$ & UNAD \\
\hline $\begin{array}{l}\text { Lingüístico } \\
\text { y Comuni- } \\
\text { cativo }\end{array}$ & $\begin{array}{l}\text { Lengua- } \\
\text { je y co- } \\
\text { munica- } \\
\text { ción }\end{array}$ & $\begin{array}{l}\text { Etnolin- } \\
\text { güística }\end{array}$ & \begin{tabular}{|l} 
Lenguaje \\
y r bilin- \\
güismo
\end{tabular} & $\begin{array}{l}\text { Antropología } \\
\text { y lingüística }\end{array}$ & Lingüística & \begin{tabular}{|l} 
Cultura \\
y comu- \\
n i c a - \\
ción
\end{tabular} \\
\hline $\begin{array}{l}\text { Investigati- } \\
\text { vo }\end{array}$ & $\begin{array}{l}\text { Investi- } \\
\text { ga ción } \\
\text { para la } \\
\text { et no e - } \\
\text { d u c a - } \\
\text { ción }\end{array}$ & $\begin{array}{l}\text { Investi- } \\
\text { gación }\end{array}$ & & & \multirow[t]{2}{*}{$\begin{array}{l}\text { Pedagogía e } \\
\text { investigación }\end{array}$} & $\begin{array}{l}\text { Investi- } \\
\text { gación }\end{array}$ \\
\hline Pedagógico & $\begin{array}{l}\text { Pedago- } \\
\text { gía y et- } \\
\text { no edu - } \\
\text { cación }\end{array}$ & $\begin{array}{l}\text { P e d a - } \\
\text { gogía y } \\
\text { didácti- } \\
\text { ca }\end{array}$ & $\begin{array}{l}S \text { a b e r } \\
\text { pedag ó- } \\
\text { gico y ca- } \\
\text { minos de } \\
\text { con o c i- } \\
\text { miento }\end{array}$ & Pedagogía & & $\begin{array}{l}\text { P e d a - } \\
\text { gogía }\end{array}$ \\
\hline \multirow[t]{2}{*}{$\begin{array}{l}\text { Ecológico- } \\
\text { tecnológico }\end{array}$} & $\begin{array}{l}\text { Ambien- } \\
\text { te y co- } \\
\text { munidad }\end{array}$ & & 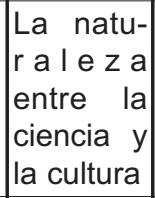 & Ambiental & & $\begin{array}{l}\text { Historia, } \\
\text { territorio } \\
\text { y desa- } \\
\text { rrollo }\end{array}$ \\
\hline & $\begin{array}{l}\text { Gestión } \\
\text { comuni- } \\
\text { taria }\end{array}$ & & & & & $\begin{array}{l}\text { A d m i - } \\
\text { nistra- } \\
\text { ción y } \\
\text { gestión } \\
\text { comuni- } \\
\text { taria }\end{array}$ \\
\hline \begin{tabular}{|l|}
$\begin{array}{l}\text { Etnológico- } \\
\text { cultural }\end{array}$ \\
\end{tabular} & & $\begin{array}{l}\text { Socio- } \\
\text { huma- } \\
\text { nística }\end{array}$ & $\begin{array}{l}\text { Cultura, } \\
\text { historia e } \\
\text { intercul- } \\
\text { turalidad }\end{array}$ & Historia & $\begin{array}{l}\text { Cultura y } \\
\text { humanida- } \\
\text { des } \\
\text { Fu e nte: }\end{array}$ & \\
\hline
\end{tabular}

folletos de difusión de los programas mencionados. (Triviño, Cerón y Ramírez: 2005)

${ }^{3}$ No se tuvo en cuenta la propuesta curricular de la Licenciatura en etnoeducación y desarrollo comunitario de la UTP por su orientación a poblaciones urbanas no indígenas.

162 
En relación con el componente de investigación, este ha sido considerado como uno de los pilares en todos los programas, tanto en el área pedagógica como en las áreas sociales, ambientales, culturales, lingüísticas y en la articulación de la escuela con saberes locales, a fin de adecuar el trabajo educativo a las realidades de los diversos contextos. Aunque es el área que más puede aportar a los procesos de formación, no se cuenta con el apoyo suficiente para los costos que representa y para la dedicación de tiempo, convirtiéndose así en otro aspecto a fortalecer. Igualmente existe poco desarrollo en investigaciones entre universidades y comunidades, de manera que permitan generar experiencias de investigación colaborativa que contribuyan al desarrollo del diálogo de saberes y la generación de nuevos conocimientos.

A pesar de las limitantes planteadas, los egresados de los programas desarrollaron hasta el año pasado alrededor de 210 trabajos de investigación en temas pedagógicos, lingüísticos, ambientales y problemas socioeconómicos, entre otros. Igualmente algunos profesores de las diferentes universidades desarrollan investigaciones que aportan a los procesos etnoeducativos.

El área ambiental y de territorio es compartido por cinco de los programas e influenciado por la estrecha relación de las poblaciones con los recursos naturales y su concepción de la naturaleza, así como por las actuales políticas y requerimientos ambientales a nivel mundial.

El componente de gestión comunitaria aparece de forma explícita solamente en dos programas. Sin embargo, en los perfiles de egresados de las otras universidades se les reconoce el rol sujetos promotores de cambio frente a las problemáticas que aquejan a las comunidades. En este espacio de formación se evidencia la dimensión política de la etnoeducación que, como ya se mencionó, hace parte de las reivindicaciones y/o el reconocimiento de la diversidad lingüística cultural del país. 
Aunque el enfoque curricular que subyace en la mayoría de los programas parece ser un modelo integrado, el trabajo interdisciplinar, la articulación de otras formas de conocimiento y de otros actores es aún un reto por asumir, dado que no es una práctica común en las universidades, e implica un reacomodamiento no solo de los profesores, sino también de las directivas y la institución en general.

No obstante, en el funcionamiento de las licenciaturas en etnoeducación, algunas universidades, han trabajado con organizaciones sociales y entes territoriales a partir de convenios para el desarrollo de los programas, lo cual ha permitido que de manera descentralizada algunas universidades tengan mayor presencia en las regiones; sin embargo, el grado de incidencia de las organizaciones en aspectos como selección de estudiantes, desarrollo académico y seguimiento de los estudiantes es mínimo, comparado con el peso que tuvieron en los procesos de profesionalización de maestros. El nexo se da más a través de los trabajos de investigación que realizan los estudiantes y por las actividades de extensión de las universidades. Hoy, después de haber transcurrido más de diez años de la creación de programas de Etnoeducación y Educación Indígena, sería muy importante evaluar los procesos desde su impacto en las comunidades y su pertinencia.

De todas maneras, la demanda por estos programas sigue siendo amplia, en tal grado que hay universidades que no solamente se descentralizaron en sus regiones sino a nivel nacional, y se ha logrado una cobertura importante; al respecto los invitamos a revisar la tabla 3 . 
Tabla 3:

Población atendida en licenciaturas en etnoeducación

\begin{tabular}{|c|c|c|}
\hline Universidad & Programa & Población atendida actualmente \\
\hline $\begin{array}{l}\text { Universidad de la } \\
\text { Amazonia, } 1992 .\end{array}$ & $\begin{array}{l}\text { Licenciatura } \\
\text { en Lingüística } \\
\text { y educación } \\
\text { indígena. }\end{array}$ & $\begin{array}{l}75 \text { estudiantes. } 53 \text { en Pu-tumayo y } \\
22 \text { en Florencia: paeces, coregua- } \\
\text { jes, ingas, kamentsá y awá.. }\end{array}$ \\
\hline $\begin{array}{l}\text { Universidad de la } \\
\text { Guajira, } 1995 .\end{array}$ & $\begin{array}{l}\text { Licenciatura } \\
\text { en Etnoedu- } \\
\text { cación para } \\
\text { Básica: len- } \\
\text { gua castella- } \\
\text { na y bilingüis- } \\
\text { mo; sociales y } \\
\text { cultura; cien- } \\
\text { cias naturales } \\
\text { y educación } \\
\text { ambiental. }\end{array}$ & $\begin{array}{l}612 \text { en total. } 163 \text { estudiantes pre- } \\
\text { sencial (59 en diurna, } 104 \text { noctur- } \\
\text { na), } 449 \text { a distancia (148 en Mai- } \\
\text { cao, } 87 \text { Riohacha, } 15 \text { Molino, } 33 \\
\text { María La Baja, } 69 \text { Manaure, } 70 \\
\text { Córdoba, } 27 \text { El Plato (Magdalena): } \\
\text { wayúu }(40 \%) \text {, cancuamos ( } 2 \%) \text {, } \\
\text { koguis }(5 \%) \text {, afrodescendientes } \\
(20 \%) \text {, mestizos (30\%), árabes, } \\
\text { arhuaco, wiwa ( } 3 \%) \text {. }\end{array}$ \\
\hline $\begin{array}{l}\text { Universidad del } \\
\text { Cauca, } 1995 .\end{array}$ & $\begin{array}{l}\text { Licenciatura } \\
\text { en Etnoedu- } \\
\text { cación. }\end{array}$ & $\begin{array}{l}230 \text { estudiantes, } 42 \% \text { indígenas } \\
\text { paeces, guambianos, yanaconas, } \\
\text { koconucos y totoróes. }\end{array}$ \\
\hline $\begin{array}{l}\text { Universidad Tec- } \\
\text { nológica de Pe- } \\
\text { reira (UTP), } 1995 .\end{array}$ & $\begin{array}{l}\text { Licenciatura } \\
\text { en Etnoedu- } \\
\text { cación y des- } \\
\text { arrollo comu- } \\
\text { nitario. }\end{array}$ & $\begin{array}{l}225 \text { estudiantes. En Pereira, urba- } \\
\text { nos de clases marginadas; en } \\
\text { Quinchía, descendientes de em- } \\
\text { beras. }\end{array}$ \\
\hline UTP, 1997. & $\begin{array}{l}\text { Licenciatura } \\
\text { en Educación } \\
\text { Indígena. }\end{array}$ & $\begin{array}{l}22 \text { indígenas bilingües, } 18 \text { hom- } \\
\text { bres y } 4 \text { mujeres: emberas chami, } \\
\text { de Risaralda (Mistrató y Pueblo } \\
\text { Rico). }\end{array}$ \\
\hline $\begin{array}{l}\text { Universidad Pon- } \\
\text { tificia Bolivaria- } \\
\text { na, } 2000 .\end{array}$ & $\begin{array}{l}\text { Licenciatura } \\
\text { en Etnoedu- } \\
\text { cación }\end{array}$ & $\begin{array}{l}761 \text { en total. } 50 \% \text { indígenas, } 25 \% \\
\text { agentes de pastoral y extranjeros, } \\
25 \% \text { afrocolombianos. } \\
\text { En Medellín ( } 328) \text {, Cauca (160 } \\
\text { paeces), Puerto Asís (114), Leticia, } \\
\text { Amazonas (110). }\end{array}$ \\
\hline
\end{tabular}




\begin{tabular}{|l|l|l|}
\hline Universidad & Programa & Población atendida actualmente \\
\hline & & $\begin{array}{l}\text { Convenio Organización Indígena } \\
\text { de Antioquia: 49 estudiantes, } \\
\text { maestros, candidatos a maestros y } \\
\text { líderes; etnias embera chamí, } \\
\text { embera dóbida, embera eyabida, } \\
\text { zenú y tule (Antioquia y Chocó). }\end{array}$ \\
\hline UNAD, 2000. & $\begin{array}{l}\text { Licenciatura } \\
\text { en Etnoedu- } \\
\text { cación }\end{array}$ & $\begin{array}{l}\text { Todos son maestros, 90\% indíge- } \\
\text { nas. } \\
23 \text { estudiantes curripacos, sikuani, } \\
\text { en Puerto Inírida (Guainía). 22 } \\
\text { estudiantes en Puerto Gaitán. } \\
22 \text { estudiantes en Manaure } \\
\text { (Cesar), Lorica (Córdoba), Mitú. } \\
\text { Varios: Medellín, Cali, Bogotá, } \\
\text { zonas de Cundinamarca, Barran- } \\
\text { quilla. }\end{array}$ \\
\hline Universidad \\
Mariana 2003.
\end{tabular}

Fuente: comunicación de los coordinadores de etnoeducación, Reunión Nacional de la Red PROEIB Andes, Bogotá, junio de 2004. (Triviño, Cerón y Ramírez: 2005)

Otro aspecto interesante frente al desarrollo de los programas es el que tiene que ver con los requisitos de ingreso, pues además de ser bachiller, se requiere haber presentado las pruebas de Estado que realiza el Instituto Colombiano para el Fomento de la Educación Superior -ICFES. El valor que se da a dicha prueba lo establece cada Universidad. No obstante, la mayoría de los programas han optado por no cuantificar el resultado, simplemente basta conque se haya presentado el examen. En otras situaciones, como en la Universidad del Cauca, se exige el puntaje mínimo, pero se le otorga un valor a la experiencia de trabajo comunitario debidamente certificada. La modali- 
dad de educación a distancia exige, además, cursar y aprobar el nivel introductoria, previo a la vinculación como estudiantes regulares de los programas.

Hace algún tiempo, los aspirantes normalmente eran personas vinculadas a procesos educativos en comunidades rurales, pero recientemente empieza a presentarse el fenómeno de vinculación de estudiantes de zonas urbanas. Igualmente, la preferencia por este tipo de licenciaturas era de los indígenas, afrodescendiente y mestizos que trabajaban en zonas de influencia de los primeros. Hoy, el reto de vincular estudiantes sin una trayectoria de trabajo y sin un rasgo identitario claramente definido, implica explorar nuevos ámbitos, que pueden enriquecer la construcción de la interculturalidad, pues con el conocimiento del otro o de los otros se posibilita su reconocimiento y el diálogo intercultural.

\section{Consideraciones finales}

Como se puede advertir, los programas han tratado de articular diferentes elementos acordes con los planteamientos de las políticas existentes sobre formación de etnoeducadores y han hecho aportes importantes para el posicionamiento de la etnoeducación en Colombia; sin embargo, el alcance de este logro institucional ha producido un descentramiento de la relación y del rol que las comunidades y organizaciones deben jugar en los procesos de formación de recursos humanos. Es claro que la educación juega un papel fundamental en el control cultural de los pueblos, pero aún las relaciones son asimétricas y por más que se haya intentado transformar el espacio académico hay todavía mucho camino por recorrer, lo cual genera tensiones. Por ejemplo, a nivel institucional se acepta la participación de los sabedores indígenas no titulados, pero no su vinculación formal, dado que no cuentan con los requisitos que exigen las instituciones académicas. 
La etnoeducación ha tratado de seguir un modelo de formación integrado acorde con las demandas de los pueblos indígenas y afrocolombianos, no segmenta el plan de estudios en asignaturas, sino en ejes, en temáticas, que casi siempre convocan la articulación de disciplinas. Este esquema es afín a los programas que se desarrollan en las comunidades desde los Planes Educativos Comunitarios PEC, pero entra en riña con las demandas de los concursos docentes actuales, que convocan campos de saberes específicos como matemáticas; humanidades, lengua castellana e idiomas extranjeros; ciencias sociales y ambientales, etc. Los concursos para etnoeducadores requieren en cambio de unos lineamientos especiales.

Los programas de etnoeducación se ven abocados a nuevas realidades, tales como: la demanda de pobladores urbanos marginales y la presencia indígena en la ciudad motivada por problemas de orden público, entre otros, que exigen una actualización conceptual, metodológica y de unas relaciones con las organizaciones sociales.

A lo anterior, podemos agregar algunos de los puntos de los planteados en el estudio sobre formación de docentes para la Educación Indígena Intercultural Bilingüe y/o Etnoeducación (Triviño, Cerón y Ramírez: 2005) que para mejorar el impacto de los programas de formación docente en la calidad de la etnoeducación, allí se proponen:

- Establecer un sistema de información en etnoeducación sobre el contexto educativo y las experiencias adelantadas y contexto educativo y pedagógico que ofrezca elementos para la formulación de acciones institucionales en etnoeducación.

- Consolidar la articulación del trabajo de los diferentes estamentos nacionales e internacionales que tienen acciones en el campo de la etnoeducación (entes territo- 
riales, universidades, organizaciones no gubernamentales, organizaciones sociales, entre otras).

- Promover el posicionamiento de las diversas experiencias de formación de formadores, como parte importante de la interlocución nacional, para la actualización de la etnoeducación como campo de saber y de práctica y para la definición de políticas públicas.

- En cuanto a los programas de formación, la mayor parte de los profesores formadores requieren de mayores recursos bibliográficos básicos y seleccionados para las culturas involucradas en esos procesos; que expresen la necesidad de incentivos serios para poner en marcha proyectos de investigación y ayudas concretas para continuar con la formación en maestrías y doctorados, en el país o en el extranjero. Se requiere adecuar la labor académica y el tiempo disponible para planificar, adaptar currículos, intercambiar información y coordinar la interrelación de los elementos que intervienen en los procesos.

- Construir una pedagogía para la diversidad cultural de América Latina. Afianzar la orientación de los programas hacia la estructuración de propuestas educativas alternativas que respondan a necesidades del contexto de diversidad cultural, antes que a la academización de los proyectos culturales.

- Lograr que los procesos de acreditación de alta calidad, a los que están sometidas las instituciones de educación superior, no signifiquen la cooptación de los programas en etnoeducación, pues hay que recordar que estos hacen parte de las propuestas de homogeneización cultural. 
- Consolidar programas de postgrado con base en las diversas problemáticas de la etnoeducación que aporten a la cualificación de recursos humanos indígenas y no indígenas y/o miembros de grupos étnicos y culturales.

- El reto para el Estado y para los movimientos sociales es incorporar, en todo el sistema educativo, elementos de interculturalidad que permitan construir una comunidad verdaderamente multicultural; pues, como lo plantea Gros (2003), no se justifica que en un país reconocido como pluricultural solo la población indígena y afroamericana sean las que reciban una educación intercultural.

\section{Segunda parte:}

\section{La etnoeducación en el marco político administrativo actual en Colombia}

A pesar de la existencia de una normatividad positiva que favorece los procesos educativos en los territorios indígenas, la aplicación de la misma por parte del gobierno no garantiza la existencia de políticas claras que permitan el avance de una educación que permita a los pueblos indígenas desarrollarse como tales.

En este sentido, valga decir que desde su origen, la creación de la legislación en etnoeducación ha sido fruto de permanentes luchas de nuestros pueblos y no de la voluntad pasiva de los gobiernos. Lo sustantivo de la legislación responde a las demandas hechas por indígenas. De esta manera, podemos resumir la situación del proceso etnoeducativo en los siguientes aspectos:

a. Políticas de gobierno/Políticas del movimiento indígena: Las políticas gubernamentales han tenido como factor común los procesos de reducción y liquidación de los pue- 
blos indígenas, situación que ha sido una constante desde la invasión europea hasta la actualidad. Ante esta circunstancia, se han propuesto y desarrollado formas permanentes de resistencia. Una de ellas ha sido la formulación e implementación de los polanes y/o proyectos de vida, como estrategia que permite el desarrollo y persistencia como pueblos hacia el futuro. Los planes de vida, en general, son una estrategia de resistencia en tanto que recogen los principios fundamentales del movimiento indígena.

Territorio.- Es el espacio decisivo para la vida indígena, dado que sin él no sería posible el desarrollo autónomo e integral como pueblo. Por eso, las luchas más grandes de la historia se han hecho por territorio; se lucha por la defensa, recuperación y ampliación territorial, desde luego con un manejo acorde con nuestros usos y procedimientos, en razón de que durante siglos hemos protegido los recursos naturales, bosques, páramos, etc., lo cual nos ha permitido una relación estrecha de armonía hombre-naturaleza. La tierra significa vida. La mayoría de los indígenas la denominamos madre.

Cultura.- Nuestro planteamiento, antes y después de la invasión, es mantener, y actualmente, recuperar los elementos culturales que nos caracterizan como pueblos indígenas, pero no para diferenciarnos de la cultura mayoritaria, sino porque nuestra sabiduría está allí para beneficio nuestro y para los demás. Nos negamos a que desaparezca nuestra lengua, elemento fundamental para mantener la cultura y la sabiduría; nos negamos a que desaparezca nuestra música y danza, nuestro vestido, nuestras formas de economía y producción, nuestros cultivos tradicionales y nuestras propias dietas alimenticias; pero más aún, nos negamos a que desaparezcan nuestra medicina tradicional y nuestros saberes ancestrales, los cuales consideramos que deben estar en igualdad de condiciones con el denominado conocimiento científico. 
Identidad.- Valoramos el proceso de identidad indígena como elemento fundamental de procesos de unidad y organización. No se entendería la existencia de un pueblo sin identidad, esta nos valora como tal y nos impulsa a seguir adelante en los procesos. Cada pueblo hace un esfuerzo por mantener su identidad, y si se ha perdido, el esfuerzo es recuperarla y, si es necesario, reconstruirla y construirla en sus aspectos políticos, económicos, sociales y culturales. Estos procesos de identidad tratamos de mantenerlos en diversas categorías y por eso no solamente nos identificamos como indígenas sino como pueblos, como organizaciones regionales y/o como organización nacional.

Autonomía.- Desde los inicios de las organizaciones indígenas venimos planteando la autonomía de las comunidades y de nuestras autoridades con base en el derecho de autodeterminación de los pueblos, con fundamento en nuestro derecho mayor pero también en el derecho establecido en la normatividad nacional e inclusive internacional. Para nosotros es claro que debemos decidir por nosotros mismos en todo aquello que nos afecte. Los planes de vida desarrollan todos los procesos a partir de la autonomía económica, social, política y cultural y en el marco de la institucionalidad, también la autonomía administrativa y financiera. Sabemos que estamos lejos de cumplir nuestro propósito, pero son y seguirán siendo los planes de vida los instrumentos y base de negociación con el Estado, a fin de que se nos garantice y se nos respete la pervivencia como pueblos y la continuidad de nuestra institucionalidad interna.

Vale decir que complementan los principios, anteriormente enunciados, dos ejes transversales que igualmente son importantes en nuestro proceso de desarrollo, estos son: la integralidad, en la medida en que la vida es íntegra y no desglosada en sectores; para nosotros la vida es un todo y asimismo son los planes de vida, integrales. El otro 
eje transversal es la interculturalidad, en tanto que no se trata de rechazar al otro, sino buscar la complementariedad de las diferentes culturas. Reconocemos que toda cultura tiene algo que aportar a la otra, el problema se presenta cuando una de ellas quiere sobreponerse sobre la otra, en un proceso de desconocimiento o invisibilización e inclusive de rechazo, que es lo que hemos sufrido los pueblos indígenas frente a la cultura mayoritaria, más conocida como Occidental.

En este contexto, la educación que requerimos es aquella que esté en función del desarrollo de dichos planes y proyectos. Estas dos posiciones riñen con la visión del Estado colombiano respecto a nuestras comunidades; en consecuencia nuestra resistencia se ha convertido en una constante lucha frente a las políticas de Estado, llámese Seguridad Democrática, privatización y en fin todas las políticas de globalización en el marco del neoliberalismo. Esa confrontación política hace que la implementación de nuestros procesos educativos, más conocidos como Educación Propia, tengan grandes dificultades, dado que el gobierno no está dispuesto a reconocer lo nuestro y nosotros tampoco a ceder los espacios ganados.

En este marco y con base en la normatividad vigente (Convenio 169 de la OIT de 1988, Ley 21 de 1991, Constitución Política de 1991 entre otras), ha sido necesario realizar acuerdos a partir del diálogo y la concertación con el gobierno nacional que permitan disminuir el conflicto. Así las cosas, en la actualidad tenemos acuerdos suscritos, muchos de ellos dentro de la categoría normativa nacional, entre los que esta el decreto 982 de 1999. Este decreto hace la declaratoria de emergencia social y económica de los pueblos indígenas del Cauca y contempla temas de salud, educación, producción y derechos humanos. Para el desarrollo de estos temas y cumplimiento de los compromisos, se acordó por una parte un Comité y por otra la reali- 
zación de mesas de trabajo con el objeto de determinar qué hacer en cada uno de los sectores.

Las mesas de concertación están conformadas por representantes de los pueblos indígenas, de las organizaciones nacionales, regionales e inclusive zonales y miembros del gobierno nacional. Allí se discuten las posiciones y propuestas de las partes hasta llegar a acuerdos.

En lo referente a educación, se viene planteando la ampliación de cobertura, contratación, infraestructura y en general políticas educativas concretas. En ese sentido se han realizado algunas mesas, las cuales han dado como resultado diversas circulares y actos administrativos con miras a organizar la educación en los pueblos indígenas; igual se vienen debatiendo a ese nivel temas como evaluación de docentes en territorios indígenas y, con mayor intensidad, la selección de maestros en territorios indígenas para efecto de vinculación a la carrera docente. En este último tema están sobre la mesa propuestas tanto del Ministerio de Educación como de los Pueblos Indígenas pero aún no se ha podido concretar el documento definitivo, sin embargo existe la intención por parte del gobierno nacional de entregar la administración educativa a los pueblos y organizaciones indígenas, que tienen la experiencia en los procesos de educación bilingüe intercultural como estrategia para la consolidación del Sistema de Educación Propia. El Programa de Educación Bilingüe Intercultural - PEBI, como programa del Consejo Regional Indígena del Cauca, discutió ampliamente estos temas en el XII Congreso y dejó algunas tareas concretas, en consecuencia, en estos momentos está haciendo la consulta respectiva a las autoridades de base y evaluando la experiencia para determinar el camino a seguir frente a estos nuevos sucesos: contratación, certificación, administración propia y en general la consolidación del Sistema Educativo Propio. 
b. Logros y retos Evaluación de maestros - Contratación de la educación: al momento el movimiento indígena ha logrado que el Estado se responsabilice del pago a maestros indígenas que, merced a la Ley 715 , deben concursar para ingresar a la carrera docente. Por supuesto que esto no se compadece con el Decreto 804 de 1995, que permite un tratamiento especial a los maestros de territorios indígenas, en razón de que la selección por parte de la comunidad y sus autoridades garantizan un maestro que se adecue y favorezca el desarrollo de los planes de vida. Por eso nuestra propuesta es que sean las autoridades indígenas y sus comunidades las que hagan los procesos de selección conforme a los usos, costumbres y procedimientos adoptados por sus propias organizaciones. En todo caso, en este momento se está negociando con el gobierno nacional, como se dijo anteriormente, un decreto que garantice la diversidad étnica y cultural, que permita que sean las comunidades y sus propias autoridades las que realicen el proceso de selección de los maestros, en territorios indígenas. Hasta ahora, al interior de las organizaciones indígenas, se han realizado mesas de trabajo conjuntas, y se ha discutido una tentativa propuesta de decreto. Hasta el presente no ha sido aceptada por el Ministerio de Educación. Estamos pendientes del resultado final.

De otro lado y también en el marco de la norma anteriormente relacionada, nuestras organizaciones, y particularmente el CRIC, ya han empezado a contratar la educación en territorios indígenas, buscando con ello brindar una educación conforme a las políticas educativas nuestras, es decir la construcción de Educación Propia, y a mediano plazo la formulación y desarrollo del Sistema de Educación Propia. Consideramos que contratando nosotros mismos, tenemos los instrumentos que nos permiten construir y desarrollar autónomamente nuestros propios procesos. Para esto nuestra propuesta tiene unos componentes fuertes en 
los aspectos de formulación y consolidación de los Proyectos Educativos Comunitarios, desarrollo de los procesos de pedagogía comunitaria, construcción de material didáctico, investigación y formación de docentes indígenas. Todo esto, junto al suministro de material didáctico, dotación de mobiliario escolar y apoyo alimentario, ayuda notablemente a la construcción de procesos de administración educativa propios, y a la consolidación del trabajo político organizativo de los pueblos, como eje importante de nuestras organizaciones.

En este proceso la organización trae experiencias de años atrás, en situaciones como:

- Selección participativa de docentes.- La organización, a través del programa y con base en la experiencia, ha fijado unos criterios para vinculación de las personas que colaboren en los territorios indígenas, tales como el origen indígena, identidad como tal, experiencia en procesos políticos y organizativos, colaboración con la comunidad y las autoridades indígenas, no tener problemas con la comunidad ni con las autoridades indígenas y no indígenas, conocimiento y participación en los procesos locales, zonales y regionales y la formación requerida para cumplir las funciones del cargo al cual se vincula, entre otros. Con base en estos criterios, la comunidad selecciona el personal que considera idóneo para el cargo; posteriormente, la consejería realiza una prueba que, para el caso de los maestros, contiene componentes pedagógicos, políticos y académicos. Se vincula a quienes alcancen los mayores puntajes. Para ser vinculado se debe obligatoriamente tener el aval de la autoridad tradicional, o en su defecto de la autoridad zonal.

- Los docentes vinculados.- No ingresan conforme al estatuto docente que reglamenta a los docentes no indígenas, 
sino que se prefirió establecer una normatividad interna propia, la cual incluye niveles diferentes de los establecidos nacionalmente y con sus respectivos salarios. El nivel y el salario resultan del puntaje de la evaluación hecha por el Programa. A estos docentes no se les deja solos. Tienen el acompañamiento por parte de coordinadores zonales, coordinadores pedagógicos y personal del equipo del Programa, con el fin de ir construyendo proyectos educativos y metodologías propios; y en lo posible pedagogías que se generan en la comunidad. Por otro lado se hace acompañamiento en la formación y cualificación del docente con el objeto de garantizar en un futuro no muy lejano la construcción del Sistema Educativo Propio.

-Para efectos de administración.- Estamos trabajando en procesos de consolidación de la administración educativa propia, por eso, en la contratación que se viene haciendo, insistimos, y más aún exigimos, que esta debe ser conforme a la canasta educativa que nosotros proponemos, la cual contiene no solo el pago de maestros, sino también temas como el mejoramiento de la calidad educativa, consolidación del sistema educativo propio, acompañamiento pedagógico, formulación y desarrollo de Proyectos Educativos Comunitarios, construcción de material didáctico, apoyo lingüístico en los centros educativos, dotación de mobiliario, formación docente, alimentación escolar y acompañamiento administrativo.

Como se puede ver, el proyecto es ambicioso y como tal requiere de una gran claridad por parte de las comunidades y autoridades, como garantía de un desarrollo adecuado de la educación en los territorios indígenas pero también para sustentarlo ante el gobierno nacional a fin de que cumpla con nuestros derechos educativos. 
c. Universidad Autónoma Indígena Intercultural: Este es el gran reto de los pueblos indígenas. Tanto la contratación como las mesas de trabajo nacional y regional esperan de nosotros respuestas a corto y mediano plazo respecto a la demanda de formación docente, administración educativa, formación política y, particularmente, formación en el campo pedagógico. Esto debido fundamentalmente a que actualmente los maestros existentes son formados desde y para la cultura mayoritaria y las universidades convencionales no ofrecen la formación que se requiere en el marco de las políticas y necesidades de los pueblos indígenas para desarrollarse como tales. Adolecemos de formadores propios en los diferentes campos, lo cual nos obliga a implementar programas de educación superior a mediano plazo en los campos requeridos para la Educación Bilingüe Intercultural. En la actualidad estamos, por una parte en el proceso de estructuración curricular para iniciar un primer programa de pedagogía comunitaria y por otra en la búsqueda de legitimación por parte del Estado de nuestra Universidad. Valga decir que en términos del derecho propio, esta Universidad ya fue creada, por mandato de las autoridades, en razón de, por una parte, a la necesidad urgente de formación superior, y por otra a que algunas zonas ya iniciaron programas a ese nivel, tales como Gestión y Administración Propia en Jambaló y el Instituto de Investigación de Tierradentro y Derecho Propio en la zona Norte. Todo esto nos lleva a realizar todo un proceso de estructuración tendiente a responder a las demandas de los pueblos indígenas.

El tema de Universidad no es un asunto que aparezca porque sí en nuestra agenda de trabajo, sino que es fruto del proceso educativo que venimos desarrollando. En un principio la urgencia era formación en nivel primario, superada esta etapa continuamos con el nivel secundario, 
pasada esta etapa y con la trayectoria que se tiene, hemos iniciado el proceso de la formación superior. Ahora, esto no solo se refiere a los espacios meramente académicos, para nosotros también es vital el espacio no académico, porque es allí donde se forman los grandes líderes: los taitas, los mayores y son ellos quienes orientan no solamente lo educativo sino también la integralidad de nuestros procesos. A esta escuela no formal debemos los logros alcanzados en la trayectoria de la lucha que venimos librando.

\section{Bibliografía}

Agreda, Antonia

1999 "La etnoeducación, una respuesta a las aspiraciones educativas de los pueblos indígenas de Colombia", en: Memorias Simposio de Etnoeducación VIII Congreso de Antropología, Universidad del Atlántico.

Arango, Roque y Enrique Sánchez

1997 Pueblos Indígenas de Colombia. Bogotá, Dirección Nacional de Planeación.

Castillo Elizabeth, Ernesto Hernández y Axel Alejandro Rojas

2005 "Los etnoeducadores: esos nuevos sujetos de la educación colombiana", en: Revista Colombiana de Educación Nro. 48. Universidad Pedagógica Nacional.

Cataño, Luz Estela y Elizabeth Castillo

2004 "La Etnoeducación como política educativa pública en el suroccidente colombiano", en: Boletín GEIM, Nro. Universidad del Cauca. 
Consejo Nacional de Acreditación -CNA. Criterios y Procedimientos para la Acreditación Previa de 1998 los Programas Académicos de Pregrado y Especializaciones en Educación. MEN-CNA.

Consejo regional Indígena del Cauca -CRIC. Programa de Educación Bilingüe e Intercultural (PEBI)

2004 ¿Qué pasaría si la escuela...? Editorial El Fuego Azul. Bogotá.

Houghton, Juan

1998 "¿A dónde apunta la etnoeducación de los pueblos indígenas?", en: Lenguas Aborígenes de Colombia Memorias 4. Educación Endógena frente a Educación Formal. Bogotá, Universidad de los Andes, pp. 51 - 67.

Jiménez, Néstor

1998 "Etnoeducación: Política oficial para la educación en comunidades indígenas", en: Lenguas Aborígenes de Colombia Memorias 4. Educación Endógena frente a Educación Formal. Bogotá, Universidad de los Andes, pp. 37 49

Lozano, Leonor, Silvio Aristizábal, Emperatriz Cahuache, Rosalba Jiménez y Francisco Ortiz

2000 Evaluación de maestros en comunidades indígenas. Bogotá, Ministerio de Educación Nacional, Octubre.

Ministerio de Educación Nacional

1987 Lineamientos Generales de Educación Indígena. Bogotá.

2004 Normatividad básica para Etnoeducación. Bogotá, Enero. 
Organización Nacional Indígena de Colombia (ONIC) 2000 "La educación como estrategia para el fortalecimiento de los proyectos y planes de vida de los pueblos indígenas", en: Abriendo caminos. Taller Seminario Internacional "Educación y Comunidad en los Pueblos Indígenas de los Países Andinos". Memorias. Compañía Gráfica Industrial Ltda. Cochabamba. 29- 42.

1998 Cartilla Planes de vida. Bogotá.

Ramírez, Teresa

2003 "Factores sociales y profesionales que afectan la identidad étnica y profesional de los maestros indígenas", en: Revista Unicauca Ciencia Nro. 7. Universidad del Cauca, pp. 64-66

Trillos, María

1996 Estudio sobre la formación de recursos humanos para el desarrollo de la Educación Intercultural Bilingüe en Colombia. Informe de estudio, mímeo, 57 p.

1998 "La Educación Indígena en Colombia -síntesis del estado del arte presentado en Antigua, Guatemala", en: Lenguas Aborígenes de Colombia. Memorias Educación Endógena frente a Educación Formal. Bogotá CCELA Universidad de los Andes, pp. 69 - 931999

Triviño Lilia, Patricia Cerón y Teresa Ramírez 2005 “Formación de docentes para la Educación Indígena Intercultural Bilingüe y/o Etnoeducación para Colombia", en: La Formación de Docentes en Educación Intercultural Bilingüe para América Latina. GTZ y Ministerio de Educación de Bolivia. CD, $44 \mathrm{p}$. 
